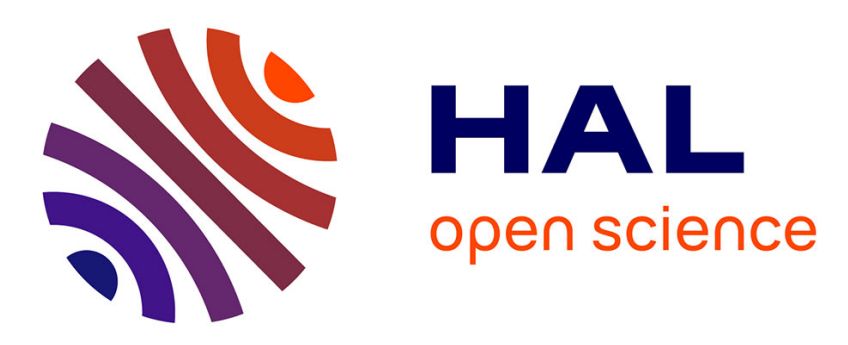

\title{
Template-Directed Synthesis of a Conjugated Zinc Porphyrin Nanoball
}

Jonathan Cremers, Renée Haver, Michel Rickhaus, Juliane Gong, Ludovic Favereau, Martin D Peeks, Tim D W Claridge, Laura Herz, Harry L Anderson

\section{- To cite this version:}

Jonathan Cremers, Renée Haver, Michel Rickhaus, Juliane Gong, Ludovic Favereau, et al.. TemplateDirected Synthesis of a Conjugated Zinc Porphyrin Nanoball. Journal of the American Chemical Society, 2018, 140 (16), 10.1021/jacs.8b02552 . hal-01768194v2

\section{HAL Id: hal-01768194}

https://hal-univ-rennes1.archives-ouvertes.fr/hal-01768194v2

Submitted on 27 Apr 2018

HAL is a multi-disciplinary open access archive for the deposit and dissemination of scientific research documents, whether they are published or not. The documents may come from teaching and research institutions in France or abroad, or from public or private research centers.
L'archive ouverte pluridisciplinaire HAL, est destinée au dépôt et à la diffusion de documents scientifiques de niveau recherche, publiés ou non, émanant des établissements d'enseignement et de recherche français ou étrangers, des laboratoires publics ou privés. 


\title{
Template-Directed Synthesis of a Conjugated Zinc Porphyrin Nanoball
}

\author{
Jonathan Cremers,${ }^{\dagger}$ Renee Haver, ${ }^{\dagger}$ Michel Rickhaus, ${ }^{\dagger}$ Juliane Q. Gong, ${ }^{\dagger}$ Ludovic Favereau, ${ }^{\dagger}$ Martin D. \\ Peeks, ${ }^{\dagger}$ Tim D. W. Claridge ${ }^{\dagger}$ Laura M. Herz,$\stackrel{\dagger}{ }$ and Harry L. Anderson $*, \dagger$ \\ ${ }^{\dagger}$ Chemistry Research Laboratory, Department of Chemistry, University of Oxford, Oxford, OX1 3TA, United Kingdom \\ *Clarendon Laboratory, Department of Physics, University of Oxford, Oxford, OX1 3PU, United Kingdom
}

Supporting Information Placeholder

\begin{abstract}
We report the template-directed synthesis of a $\pi$-conjugated 14-porphyrin nanoball. This structure consists of two intersecting nanorings of 6 and 10 porphyrin units. Fluorescence up-conversion spectroscopy experiments demonstrate that electronic excitation delocalizes over the whole $3 \mathrm{D} \pi$ system in less than $0.3 \mathrm{ps}$, if the nanoball is bound to its templates, or over $2 \mathrm{ps}$ if the nanoball is empty.
\end{abstract}

Spurred by the discovery of buckminsterfullerene, ${ }^{1}$ chemists have sought rational strategies for the synthesis of $3 \mathrm{D} \pi$ conjugated geodesic cages. Stepwise chemical synthesis has not yet been used to prepare any fullerenes, except $\mathrm{C}_{60}$ (ref. 2), but several fullerene-like ball-shaped $\pi$-conjugated hydrocarbons have been synthesized recently. ${ }^{3}$ The high dimensionality of these $\pi$-systems is expected to enhance their electronic delocalization, compared with $1 \mathrm{D}$ or 2D molecular semiconductors. ${ }^{4-6}$ Shape-persistent molecular cages are also in demand for their gas adsorption properties, which mimic those of zeolites. $^{7}$ The best routes to molecular cages or capsules use reversible reactions that allow error correction, such as metal coordination $^{8}$ or boronic ester condensation, ${ }^{9}$ but these reactions do not produce $\pi$-conjugated connections. In principle, reversible reactions such as imine formation, ${ }^{10}$ alkene metathesis $^{11}$ and alkyne metathesis ${ }^{12}$ could be used to construct $\pi$ conjugated cages, but so far the cages made by these reactions lack long-range conjugation. ${ }^{7,10-12}$ Template-directed coupling, under kinetic control, is an alternative strategy for preparing large macrocycles and cages. ${ }^{13}$ Here we show how simple molecular templates can be used to synthesize the first fully $\pi$ conjugated porphyrin ball $\boldsymbol{b}$-P14 (Figure 1). This 14-porphyrin prolate ellipsoidal cage consists of two perpendicular intersecting conjugation pathways, containing 6 and 10 porphyrin units respectively. Structures of this type are valuable models for photosynthetic light-harvesting systems. ${ }^{13-15}$ When all 14 porphyrin units in $\boldsymbol{b}$-P14 are bound to templates, locking the conformation, excited state energy delocalization occurs over the whole system within $0.3 \mathrm{ps}$, whereas in the absence of the templates excitation is distributed over the ball with a time constant of about 2 ps.
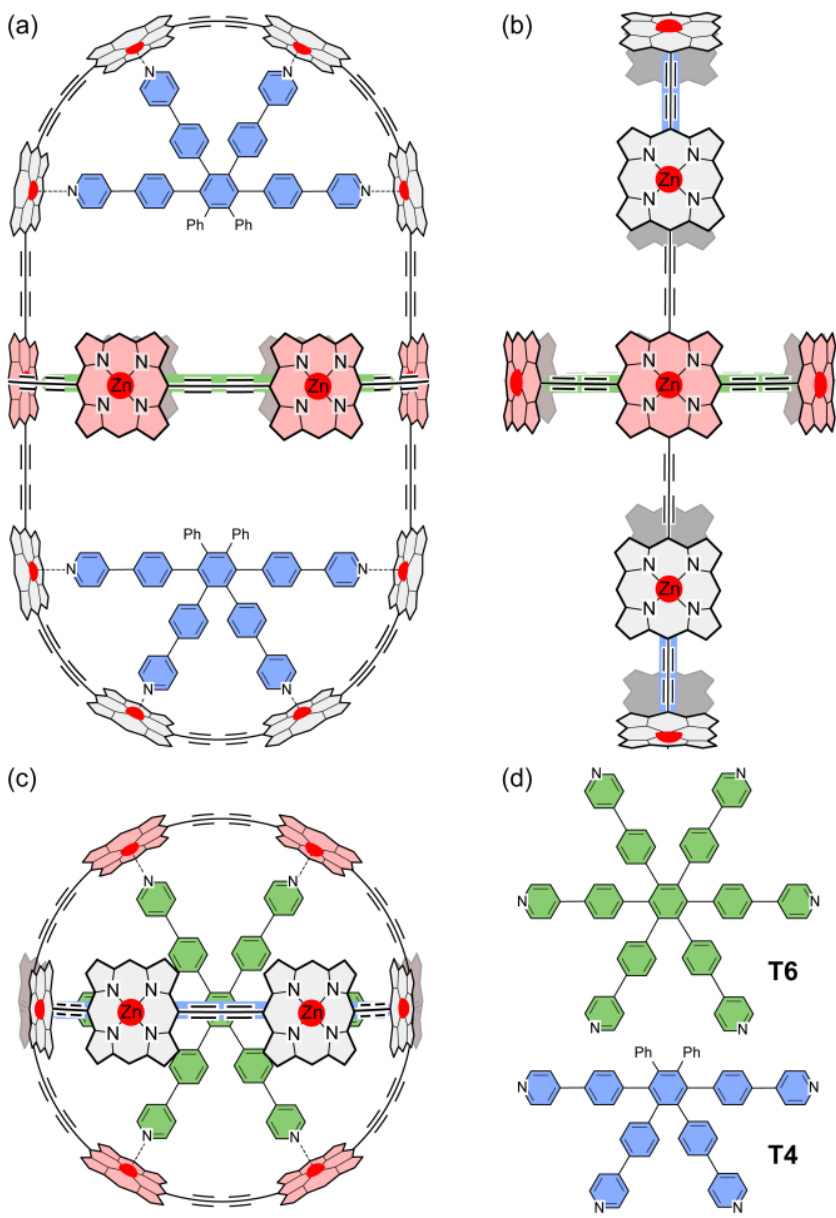

Figure 1. (a)-(c) Three orthogonal views of the structure of the 14-porphyrin ball template complex $\boldsymbol{b}$-P14·T6・(T4) $)_{2}$ and (d) the templates T6 and T4. The meso-aryl side groups on the porphyrins are omitted for clarity.

The porphyrin nanoball $\boldsymbol{b}$-P14 was synthesized as shown in Figure 2, using templates T6 and T4 (Figure 1). This route starts from a 6-porphyrin nanoring template complex with four terminal alkyne substituents, $\boldsymbol{c}-\mathbf{P 6}(\mathbf{H})_{4} \cdot \mathbf{T 6}$, which was prepared as reported previously. ${ }^{16}$ This ring was coupled to four porphyrin dimers P2-CPDIPS, followed by removal of the CPDIPS protecting groups, to give the extended nanoring

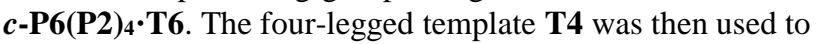




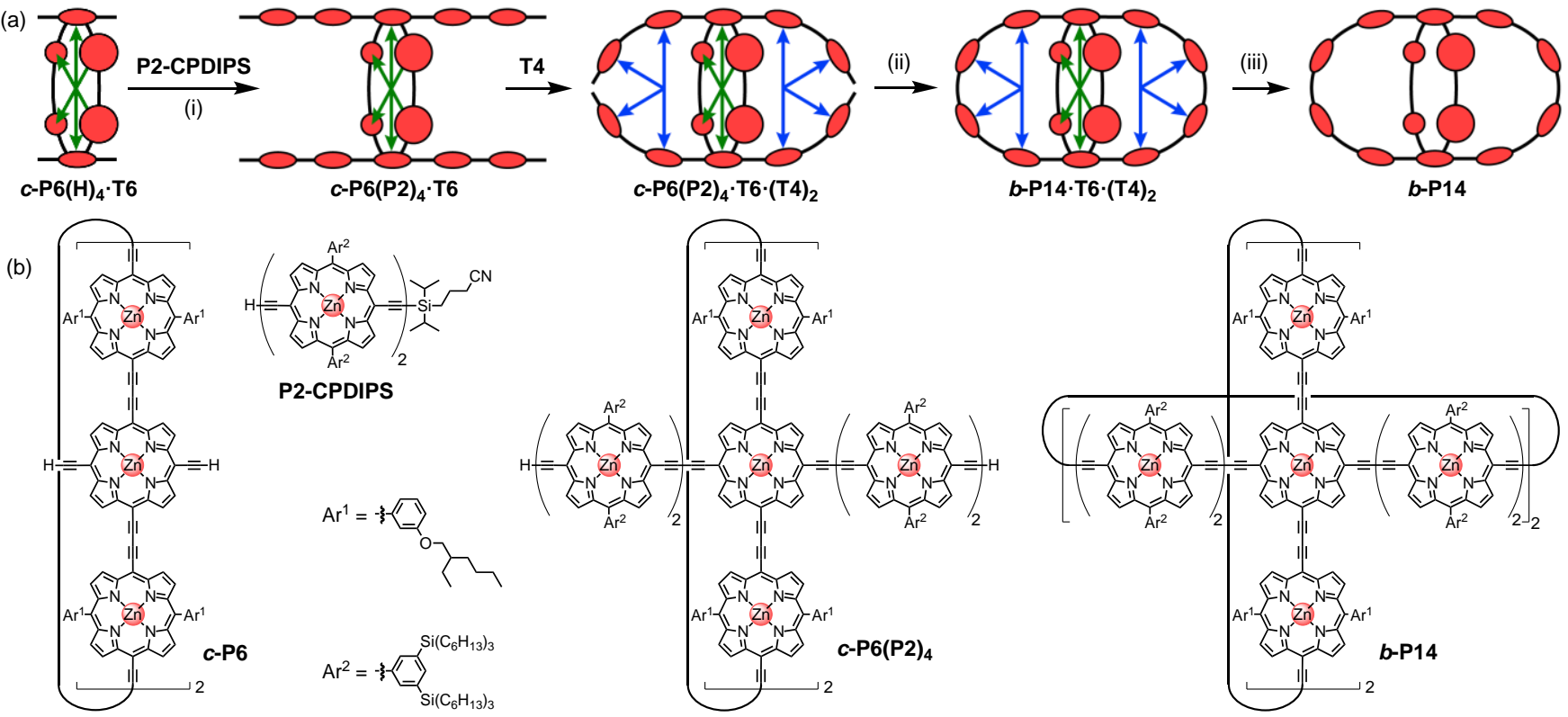

Figure 2. (a) Schematic synthetic route for $\boldsymbol{b}$-P14. Reaction conditions: (i) P2-CPDIPS, $\mathrm{Pd}\left(\mathrm{PPh}_{3}\right)_{2} \mathrm{Cl}_{2}, \mathrm{CuI}_{1}, 1,4-$ benzoquinone, $\mathrm{CHCl}_{3} / i$ $\mathrm{Pr}_{2} \mathrm{NH}, 41 \%$; then TBAF, $\mathrm{CH}_{2} \mathrm{Cl}_{2}, 97 \%$; (ii) $\mathrm{Pd}\left(\mathrm{PPh}_{3}\right)_{2} \mathrm{Cl}_{2}, \mathrm{CuI}, 1,4-$ benzoquinone, $\mathrm{CHCl}_{3} / i-\mathrm{Pr}_{2} \mathrm{NH}$, 51\%; (iii) DABCO, size exclusion chromatography, toluene/pyridine, 100\%. (b) Chemical structures of $c$-P6-(H) $)_{4}$, P2-CPDIPS, $\boldsymbol{c}$-P6(P2) $)_{4}$ and $\boldsymbol{b}$-P14.

close the 10-porphyrin ring, yielding the bicyclic nanoball $\boldsymbol{b}$ P14·T6-(T4)2. The templates can readily be displaced from this cage by high concentrations of a competing ligand ${ }^{17}$ quinuclidine or DABCO remove both templates, giving $\boldsymbol{b}$-P14, whereas pyridine selectively removes $\mathbf{T 4}$, giving $\boldsymbol{b}$-P14·T6. Both $\boldsymbol{b}$-P14 and $\boldsymbol{b}$-P14·T6 were fully characterized (see SI). Two types of aryl solubilizing groups were used in this molecular design ( $\mathrm{Ar}^{1}$ and $\mathrm{Ar}^{2}$, Figure 2) so as to confer high solubility while avoiding excessive steric congestion.

Gel permeation chromatography (GPC) confirmed the purity of the nanoball and showed that its molecular weight is in the expected range (ca. $20 \mathrm{kDa}$ ). The ${ }^{1} \mathrm{H}$ NMR spectrum of $\boldsymbol{b}$ P14. T6. (T4) 2 in $\mathrm{CDCl}_{3}$ at $298 \mathrm{~K}$ is consistent with the expected $D_{2 \mathrm{~h}}$ gross symmetry and all the signals were assigned by COSY and NOESY spectroscopy, except for unresolved aliphatic multiplets in the $0.4-2.0 \mathrm{ppm}$ region (see SI). This ${ }^{1} \mathrm{H}$ NMR spectrum shows that the nanoball consists of a mixture of conformers with ethylhexyl chains pointing into and out of the cavity; these rotamers are in slow exchange on the NMR timescale, with ca. $40 \%$ of the alkoxy-chains pointing towards the center of the ball. This ratio scarcely changes on removal of the $\mathbf{T} 4$ templates. When all the templates are removed, the porphyrins of the 6-ring rotate rapidly, simplifying the NMR spectrum. Diffusion-ordered ${ }^{1} \mathrm{H}$ NMR spectroscopy (DOSY) experiments show that $\boldsymbol{b}$-P14 $\cdot \mathbf{T 6} \cdot(\mathbf{T 4})_{2}$ has a diffusion coefficient of $1.52 \times 10^{-10} \mathrm{~m}^{2} \mathrm{~s}^{-1}\left(700 \mathrm{MHz}, 298 \mathrm{~K}, \mathrm{CDCl}_{3}\right)$, which corresponds to a hydrodynamic radius of about $27 \AA$, calculated using the Stokes-Einstein equation for a spherical molecule.

The UV-vis-NIR spectrum of $\boldsymbol{b}$-P14·T6・(T4) 2 (Figure 3a, black curve) is essentially the sum of the absorption spectra of its two component rings, as modeled by $\boldsymbol{c}$-P6 $\mathbf{T 6}$ (the $D_{6 \mathrm{~h}}$ ring complex, with 3,5-bis(trihexylsilyl)phenyl substituents) ${ }^{18}$ and c-P10.(T5) 2 (where T5 is the version of T6 with five pyridyl sites), ${ }^{16-20}$ although the absorption spectrum of $\boldsymbol{b}$-P14 $\cdot$ T6 $\cdot(\text { T4 })_{2}$ is slightly red-shifted, demonstrating greater $\pi$-conjugation (SI

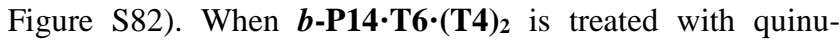
clidine to displace the templates, two distinct denaturation processes are observed in the UV-vis-NIR titration (Figure 3): At quinuclidine concentrations of 3-30 mM (Figure $3 \mathrm{~b}$ ), the T4 units are displaced leading to disappearance of the sharp peak at $883 \mathrm{~nm} ;{ }^{19-21}$ this peak is associated with the templatebound conformation of the 10-porphyrin ring. At quinuclidine concentrations of 30-300 mM (Figure 3c), the central T6 unit is displaced causing disappearance of the distinctive threefinger pattern in the $\mathrm{Q}$ band of the 6-porphyrin ring component. All these spectral changes reflect the greater flexibility, and wider distribution of porphyrin-porphyrin dihedral angles, upon template removal.

Analysis of the denaturation binding isotherms ${ }^{13 c, 17,21}$ (Figure 3 ) reveals that the association constants for binding of $\mathbf{T 4}$ and T6 to $\boldsymbol{b}$-P14 to form $\boldsymbol{b}$-P14-T6 $(\mathbf{T} 4)_{2}$ are $(1.8 \pm 0.2) \times 10^{22}$ $\mathrm{M}^{-1}$ for $\mathbf{T} 4$ and $(5.5 \pm 1.2) \times 10^{37} \mathrm{M}^{-1}$ for $\mathbf{T 6}$, in toluene at 298 $\mathrm{K}$. This analysis assumes that the denaturation processes for each template (T4 and T6) are essentially all-or-nothing two state equilibria (i.e. intermediate partially denatured species do not build up to high concentrations); this assumption is supported by the isosbestic nature of the UV-vis-NIR titration and the good fits of the curves to the calculated isotherm for a twostate equilibrium (Figure 3b,c). The binding strength of T6 is roughly an order of magnitude stronger in the ball than in a comparable 6-ring system, ${ }^{17}$ which can be attributed to the conformational preorganization provided by the 10 -porphyrin ring. 

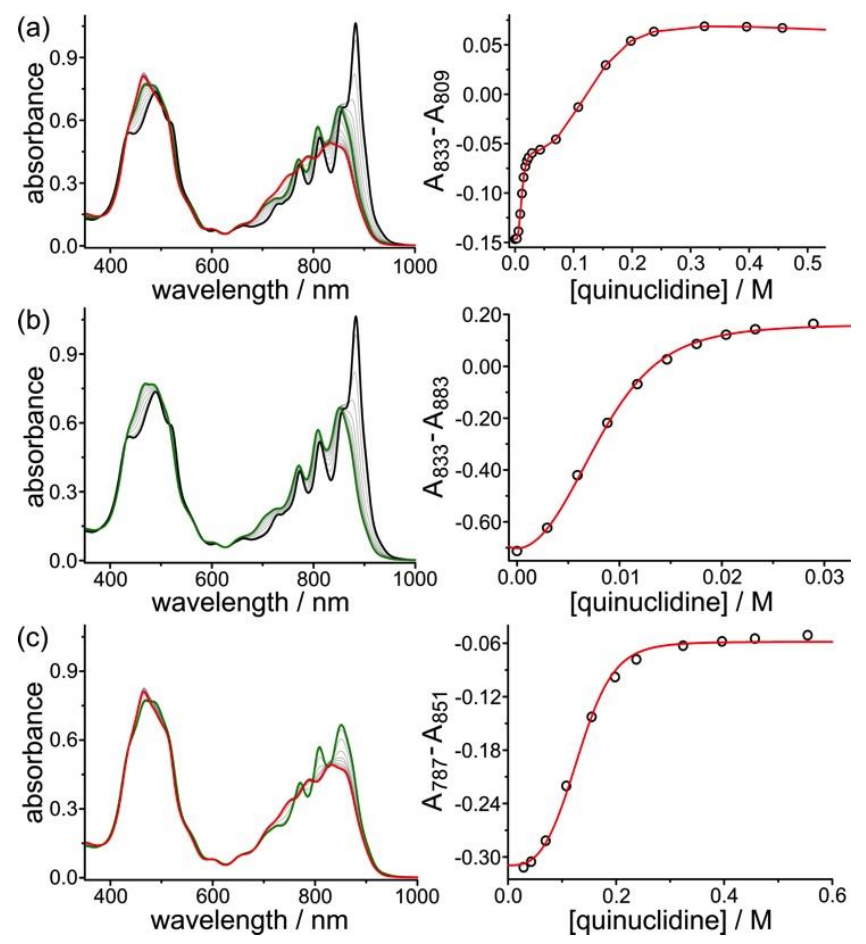

Figure 3. UV-vis-NIR denaturation titration of the $\boldsymbol{b}$ P14 $\cdot$ T6 $($ T4) 2 complex with quinuclidine (toluene, $298 \mathrm{~K}$ ). (a) Full titration, T4 is displaced first (black to green) followed by the displacement of T6 (green to red). The two phases of the titration are shown in (b) and (c), with the experimental (black circles) and calculated isotherms (red lines) shown on the right.

The UV-vis-NIR absorption and fluorescence spectra of $\boldsymbol{b}$ P14. T6 (T4) 2 and $\boldsymbol{b}$-P14 are compared in Figure 4. The more rigid conformation of the template-bound ball is reflected by its sharper and more red-shifted absorption and emission spectra. ${ }^{19-21}$ Fluorescence up-conversion spectroscopy experiments reveal that the excited states delocalize across the two perpendicular ring planes in the nanoball on an ultrafast timescale. The fluorescence anisotropy dynamics of $\boldsymbol{b}$-P14, with and without templates, are shown in Figure 4c. The template complex, $\boldsymbol{b}$-P14·T6 $(\mathbf{T} 4)_{2}$ (black points), exhibits a constant and very low anisotropy $(\gamma=0.02)$ over the time range of this experiment (0-10 ps; time resolution $0.3 \mathrm{ps}$ ), showing that the excited state delocalizes in three dimensions within $0.3 \mathrm{ps}$. In contrast, $\boldsymbol{b}$-P14-T6 (green points) and $\boldsymbol{b}$-P14 (red points) show a fast initial drop in anisotropy within the first 5 ps from $\gamma=$ 0.1 towards $\gamma \approx 0$. This fast depolarization resembles the anisotropy decay in porphyrin nanorings with $>24$ porphyrin units. ${ }^{15}$ The initial anisotropy of 0.1 suggests that upon excitation, an exciton is delocalized over a full ring and that both absorption and emission transition dipoles are polarized in the ring plane. After ultrafast relaxation, the exciton localizes and migrates rapidly around the entire porphyrin nanoball. Contributions from emission components polarized in both planes thus result in an anisotropy close to zero. Without the templates, exciton migration is slower, resulting in the observed anisotropy decays, whereas in $\boldsymbol{b}$-P14 $\mathbf{T 6} \cdot(\mathbf{T} 4)_{2}$ the anisotropy decay is faster than the time resolution of the experiment. This behavior is very different from that of the nanorings $\boldsymbol{c}$-P6·T6, $\boldsymbol{c}$-P6 and $\boldsymbol{c}$-P10, which exhibit anisotropies of near 0.1 (re- maining constant during 10 ps after excitation), in agreement with theoretical predictions for an excited state that is delocalized over a 2 D ring. ${ }^{15,16,18,20,22}$

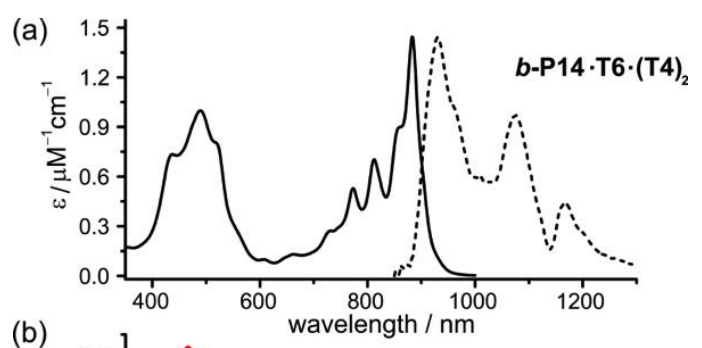

(b)

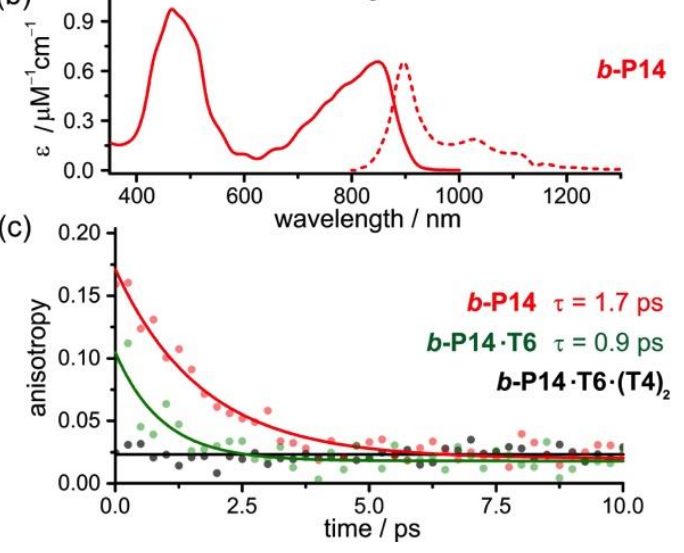

Figure 4. UV-vis-NIR absorption (solid line) and fluorescence (dashed line) spectra of (a) $\boldsymbol{b}$-P14·T6 $(\mathbf{T} 4)_{2}$ and (b) $\boldsymbol{b}$-P14 (toluene, $298 \mathrm{~K})$. The dip at $1130-1170 \mathrm{~nm}$ corresponds to solvent absorption. (c) First order fits of the fluorescence anisotropy decay. Solutions of $\boldsymbol{b}$-P14·T6-(T4) 2 (black), $\boldsymbol{b}$-P14·T6 (green) and $\boldsymbol{b}$-P14 (red) were excited at $820 \mathrm{~nm}$ and emission was detected at $950 \mathrm{~nm}$.

The prolate shape of $\boldsymbol{b}$-P14·T6-(T4) $)_{2}$ and $\boldsymbol{b}$-P14 is reminiscent of $\mathrm{C}_{70}$ fullerene. While $\mathrm{C}_{60}$ fullerene has complete polarization memory loss with zero fluorescence anisotropy, $\mathrm{C}_{70}$ displays excitation-wavelength dependent anisotropy values ranging between -0.2 and 0.1 , because emission polarized in the $x-y$ plane is energetically favorable as a result of geometrical deformation. ${ }^{23}$ However, $\boldsymbol{b}$-P14 $\cdot$ T6 $($ T4) 2 and $\boldsymbol{b}$-P14 do not display any significant changes in anisotropy with excitation wavelength in the range of 760-880 $\mathrm{nm}$, probably because the absorption features of their two constituent rings broadly overlap and the emission may be polarized in both ring planes. DFT calculations (B3LYP/6-31G*) indicate that the HOMO of $\boldsymbol{b}$-P14 is distributed over the entire $\pi$-system (Figure 5), albeit with a higher density on the 6-ring and particularly the tetraalkynylporphyrins. The LUMO and LUMO+1 are located exclusively on the 6-ring and the 10-ring, respectively, with nearly identical energies. Time-dependent DFT calculations (B3LYP/6-31G*) were carried out to model the electronic excited states of $\boldsymbol{b}$-P14. Natural transition orbital plots (Tables S4-S12) show that the two lowest energy singlet excited states $\left(S_{1}\right.$ and $\left.S_{2}\right)$ are mainly localized in the 6-porphyrin and 10porphyrin ring components, respectively. The transitions from $\mathrm{S}_{0}-\mathrm{S}_{1}$ and $\mathrm{S}_{0}-\mathrm{S}_{2}$ are dipole-forbidden $(f=0)$, whereas transitions to $S_{3}, S_{4}$ and $S_{5}$ are allowed $(f=0.13,5.12$ and 0.83 , respectively) and these excited states are distributed over all 14 porphyrins. These calculations are in line with the observa- 
tion that excitation delocalizes between the two rings within the ball on a timescale of less than $300 \mathrm{fs}$. The dimensions of the calculated geometry of $\boldsymbol{b}$-P14 are $52.7 \AA$, $27.6 \AA$ and 23.9 $\AA$ (measured as the diameter along the $D_{2 \mathrm{~h}}$ symmetry axes, without including aryl side chains).

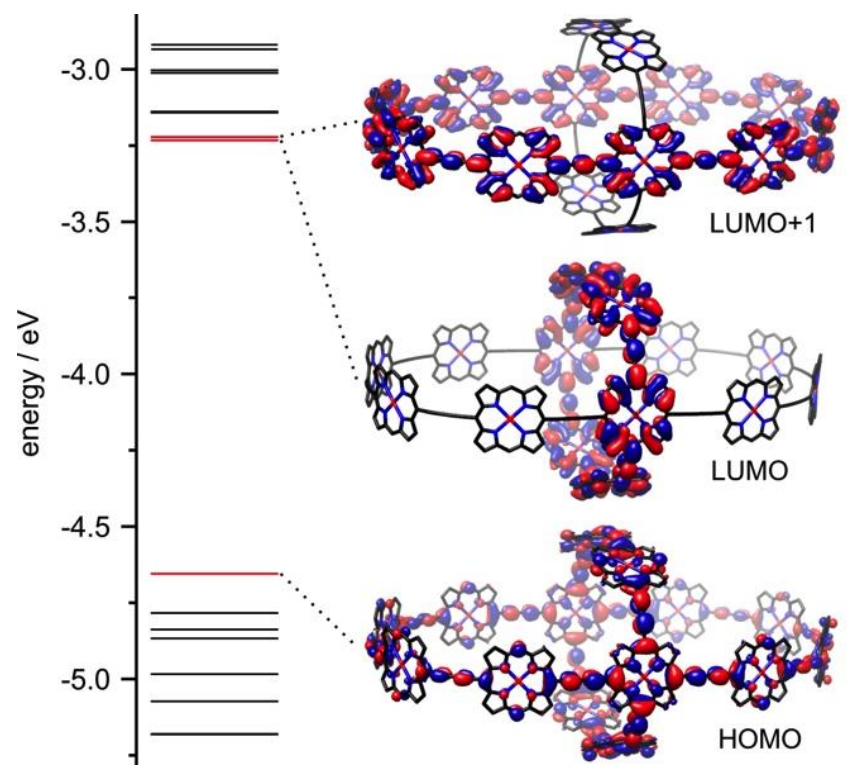

Figure 5. LUMO+1 (-3.22 eV), LUMO (-3.23 eV) and HOMO $(-4.66 \mathrm{eV})$ of $\boldsymbol{b}$-P14 calculated at the B3LYP/6-31G* level of theory with Grimme's dispersion correction, GD3, shown at a density isovalue of 0.008 a.u. together with their corresponding energy levels. Aryl groups were replaced with hydrogen atoms to simplify the calculations.

In summary, we have synthesized a fully $\pi$-conjugated three-dimensional 14-porphyrin nanoball by a template directed approach. UV-vis-NIR titrations show that the templates bound within the cavity can be removed successively by the addition of a competing ligand. Fluorescence upconversion spectroscopy reveals ultrafast electronic delocalization between the two perpendicular ring planes in the porphyrin ball. The fluorescence anisotropy approaches zero, indicating that excitation rapidly migrates between the two ring components of the nanoball.

\section{ASSOCIATED CONTENT}

Supporting Information. Synthetic procedures, characterization data, binding studies, NMR assignments, fluorescence spectroscopy and calculated geometries. The Supporting Information is available free of charge at http://pubs.acs.org.

\section{AUTHOR INFORMATION}

\section{Corresponding Author}

harry.anderson@chem.ox.ac.uk.

\section{Funding Sources}

No competing financial interests have been declared.

\section{ACKNOWLEDGMENT}

We thank the ERC (320969), EPSRC and the Swiss National Science Foundation (P2BSP2_168919) for funding, the EPSRC UK National Mass Spectrometry Facility at Swansea University for MALDI spectra and the University of Oxford Advanced Research Computing facility (ARC, http://dx.doi.org/10.5281/zenodo.22558) for support.

\section{REFERENCES}

(1) Kroto, H. W.; Heath, J. R.; O’Brien, S. C.; Curl, R. F.; Smalley, R. E. Nature 1985, 318, 162 .

(2) (a) Scott, L. T.; Boorum, M. M; McMahon, B. J.; Hagen, S.; Mack, J.; Blank, J.; Wegner, H.; de Meijere, A. Science 2002, 295, 1500. (b) Kabdulov, M.; Jansen, M.; Amsharov, K. Yu. Chem. Eur. J. 2013, 19, 17262. (c) Greisch, J.-F.; Amsharov, K. Yu.; Weippert, J.; Weis, P.; Böttcher, A.; Kappes, M. M. J. Am. Chem. Soc. 2016, 138, 11254.

(3) (a) Matsui, K.; Segawa, Y.; Namikawa, T.; Kamada, K.; Itami, K. Chem. Sci. 2013, 4, 84. (b) Kayahara, E.; Iwamoto, T.; Takaya, H.; Suzuki, T.; Fujitsuka, M.; Majima, T.; Yasuda, N.; Matsuyama, N.; Seki, S.; Yamago, S. Nat. Commun. 2013, 4, 2694. (c) Matsui, K.; Segawa, Y.; Itami, K. J. Am. Chem. Soc. 2014, 136, 16452. (d) Ikemoto, K.; Kobayashi, R.; Sato, S.; Isobe, H. Angew. Chem. Int. Ed. 2017, 56, 6511.

(4) Gutzler, R.; Perepichka, D. F. J. Am. Chem. Soc. 2013, 135, 16585.

(5) Peeks, M. D.; Tait, C. E.; Neuhaus, P.; Fischer, G. M.; Hoffmann, M.; Haver, R.; Cnossen, A.; Harmer, J. R.; Timmel, C. R.; Anderson, H. L. J. Am. Chem. Soc. 2017, 139, 10461.

(6) Ball, M.; Zhong, Y.; Fowler, B.; Zhang, B.; Li, P.; Etkin, G.; Paley, D. W.; Decatur, J.; Dalsania, A. K.; Li, H.; Xiao, S.; Ng, F.; Steigerwald, M. L.; Nuckolls, C. J. Am. Chem. Soc. 2016, 138, 12861.

(7) (a) Zhang, G.; Masteralerz, M. Chem. Soc. Rev. 2014, 43, 1934. (b) Hasell, T.; Cooper, A. I. Nat. Rev. Mater. 2016, 1, 16053. (c) Santolini, V.; Miklitz, M.; Berardo, E.; Jelfs, K. E. Nanoscale 2017, 9, 5280.

(8) (a) Olenyuk, B.; Levin, M. D.; Whiteford, J. A.; Shield, J. E.; Stang, P. J. J. Am. Chem. Soc. 1999, 121, 10434. (b) Sun, Q.-F.; Iwasa, J.; Ogawa, D.; Ishido, Y.; Sato, S.; Ozeki, T.; Sei, Y.; Yamaguchi, K.; Fujita, M. Science 2010, 1144.

(9) Zhang, G.; Presly, O.; White, F.; Oppel, I. M.; Mastalerz, M. Angew. Chem. Int. Ed. 2014, 53, 5126.

(10) Rue, N. M.; Sun, J.; Warmuth, R. Isr. J. Chem. 2011, 51, 743.

(11) Zhu, B.; Chen, H.; Lin, W.; Ye, Y.; Wu, J.; Li, S. J. Am. Chem. Soc. 2014, 136, 15126.

(12) (a) Zhang, C.; Wang, Q.; Long, H.; Zhang, W. J. Am. Chem. Soc. 2011, 133, 20995. (b) Lee, S.; Yang, A.; Moneypenny, T. P., II; Moore, J. S. J. Am. Chem. Soc. 2016, 138, 2182.

(13) (a) O'Sullivan, M. C.; Sprafke, J. K.; Kondratuk, D. V.; Rinfray, C.; Claridge, T. D.; Saywell, A.; Blunt, M. O.; O'Shea, J. N.; Beton, P. H.; Malfois, M.; Anderson, H. L. Nature 2011, 469, 72. (b) Neuhaus, P.; Cnossen, A.; Gong, J. Q.; Herz, L. M.; Anderson, H. L. Angew. Chem. Int. Ed. 2015, 54, 7344. (c) Favereau, L.; Cnossen, A.; Kelber, J. B.; Gong, J. Q.; Oetterli, R. M.; Cremers, J.; Herz, L. M.; Anderson, H. L. J. Am. Chem. Soc. 2015, 137, 14256.

(14) (a) Wasielewski, M. R. Acc. Chem. Res. 2009, 42, 1910. (b) Aratani, N.; Kim, D.; Osuka, A. Acc. Chem. Res. 2009, 42, 1922.

(15) Parkinson, P.; Kondratuk, D. V.; Menelaou, C.; Gong, J. Q.; Anderson, H. L.; Herz, L. M. J. Phys. Chem. Lett. 2014, 5, 4356.

(16) Gong, J. Q.; Favereau, L.; Anderson, H. L.; Herz, L. M. J. Phys. Chem. Lett. 2016, 7, 332.

(17) Hogben, H. J.; Sprafke, J. K.; Hoffmann, M.; Pawlicki, M.; Anderson, H. L. J. Am. Chem. Soc. 2011, 133, 20962.

(18) Sprafke, J. K.; Kondratuk, D. V.; Wykes, M.; Thompson, A. L.; Hoffmann, M.; Drevinskas, R.; Chen, W.-H.; Yong, C. K.; Kärnbratt, J.; Bullock, J. E.; Malfois, M.; Wasielewski, M. R.; Albinsson, B.; Herz, L. M.; Zigmantas, D.; Beljonne, D.; Anderson, H. L. J. Am. Chem. Soc. 2011, 133, 17262

(19) Liu, S.; Kondratuk, D. V.; Rousseaux, S. A. L.; Gil-Ramírez, G.; O'Sullivan, M. C.; Cremers, J.; Claridge, T. D. W.; Anderson, H. L. Angew. Chem. Int. Ed. 2015, 54, 5355.

(20) Gong, J. Q.; Parkinson, P.; Kondratuk, D. V.; Gil-Ramírez, G.; Anderson, H. L.; Herz, L. M. J. Phys. Chem. C 2015, 119, 6414.

(21) Cremers, J.; Richert, S.; Kondratuk, D. V.; Claridge, T. D. W.; Timmel, C. R.; Anderson, H. L. Chem. Sci. 2016, 7, 6961. 
(22) Yong, C.-K.; Parkinson, P.; Kondratuk, D. V.; Chen, W.-H.; Stannard, A.; Summerfield, A.; Sprafke, J. K.; O'Sullivan, M. C.; Beton, P. H.; Anderson, H. L.; Herz, L. M. Chem. Sci. 2015, 6, 181.

(23) Fedorov, A.; Berberan-Santos, M. N.; Lefèvre, J.-P.; Valeur, B. Chem. Phys. Lett. 1997, 267, 467. 
TOC graphic:

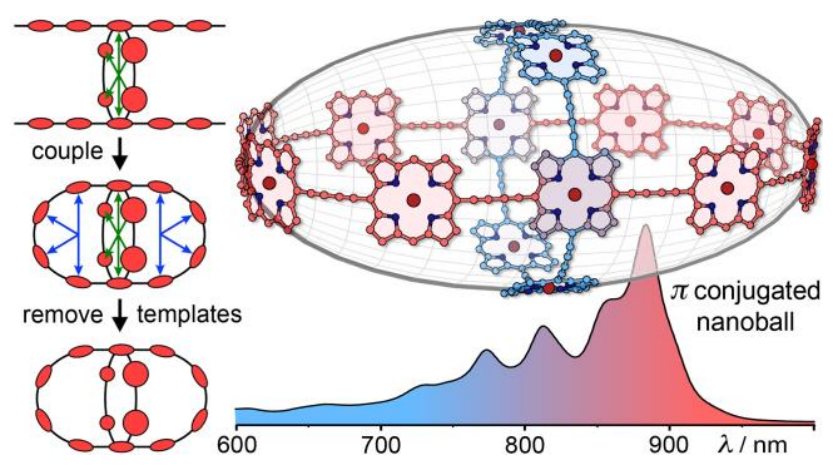

